\title{
A Molecular Antenna Coordination Polymer from Cadmium(II) and 4,4'-Bipyridine Featuring Three Distinct Polymer Strands in the Crystal
}

\section{Rüdiger W. Seidel ${ }^{1, *}$, Richard Goddard ${ }^{2}$, Bodo Zibrowius ${ }^{2}$ and Iris M. Oppel ${ }^{3}$}

1 Lehrstuhl für Analytische Chemie, Ruhr-Universität Bochum, Universitätstrasse 150, 44780 Bochum, Germany

2 Max-Planck-Institut für Kohlenforschung, Kaiser-Wilhelm-Platz 1, 45470 Mülheim an der Ruhr, Germany; E-Mails: goddard@mpi-muelheim.mpg.de (R.G.);

zibrowius@mpi-muelheim.mpg.de (B.Z.)

3 Institut für Anorganische Chemie, Rheinisch-Westfälische Technische Hochschule Aachen, Landoltweg 1, 52074 Aachen, Germany; E-Mail: iris.oppel@ac.rwth-aachen.de (I.M.O.)

* Author to whom correspondence should be addressed; E-Mail: Ruediger.Seidel@rub.de; Tel.: +49-234-32-281-94; Fax: +49-234-32-144-20.

Received: 26 July 2011; in revised form: 18 August 2011 / Accepted: 31 August 2011 / Published: 5 September 2011

\begin{abstract}
Reaction of cadmium perchlorate and the prototypical linear bridging ligand 4,4'-bipyridine (4,4'-bipy) in an ethanol/water mixture affords the one-dimensional coordination polymer, $\left[\left\{\mathrm{Cd}(\mu-4,4 \text { '-bipy })(4,4 \text { '-bipy })_{2}\left(\mathrm{H}_{2} \mathrm{O}\right)_{2}\right\}\left(\mathrm{ClO}_{4}\right)_{2} \cdot 2 \text { 4,4'-bipy } \cdot 4.5 \mathrm{H}_{2} \mathrm{O}\right]_{\mathrm{n}}$ (1). The $\mathrm{Cd}^{2+}$ ions adopt an octahedral coordination sphere and are joined into linear chains by 4,4'-bipy via two trans coordination sites. The remaining two trans sites in the equatorial plane carry terminally monodentate-bound 4,4'-bipy ligands, resulting in a molecular antenna arrangement. The two axial sites of each $\mathrm{Cd}^{2+}$ ion are occupied by aqua ligands. Compound $\mathbf{1}$ crystallizes in the non-centrosymmetric, monoclinic space group $C 2$ with three similar, crystallographically independent, cationic coordination polymer strands in the unit cell, which essentially differ only in the conformations of the 4,4'-bipyridyl ligands. Consistent with the similarity of the local coordination environments of the three independent $\mathrm{Cd}$ atoms in the structure, ${ }^{113} \mathrm{Cd}$ MAS NMR spectroscopy reveals a single resonance line at $89 \mathrm{ppm}$.
\end{abstract}


Keywords: coordination polymer; crystal engineering; crystal structure; cadmium; 4,4'-bipyridine

\section{Introduction}

Coordination polymers have attracted increasing attention since the early 1990s. This interest is largely due to their fascinating structures and potential applications in such fields as ion exchange, gas storage, separation, polymerization, heterogeneous catalysis, luminescence, non-linear optics and magnetism [1-11]. 4,4'-Bipyridine (4,4'-bipy) is a prototypical exo-bidentate, rigid linear bridging ligand and has been widely used in crystal engineering of coordination polymers [12]. It has not only played a crucial role in the advancement of coordination polymers [13] but also in the development of discrete (0D) metallosupramolecular compounds [14]. Scheme 1 depicts the most common topological motifs in 1D and 2D coordination polymers containing 4,4'-bipy as bridging ligand. 3D coordination networks propagated exclusively by 4,4'-bipy (e.g., diamondoid or $4^{2} \times 8^{2}$ networks) are relatively few in number in comparison with $1 \mathrm{D}$ and $2 \mathrm{D}$ coordination polymers formed by this ligand [12].

Scheme 1. Most frequently observed topological motifs in coordination polymers propagated by 4,4'-bipy (black connectors) and metal nodes (large grey spheres): (a) linear chain, (b) zig-zag chain, (c) ladder, (d) $(4,4)$ square grid.
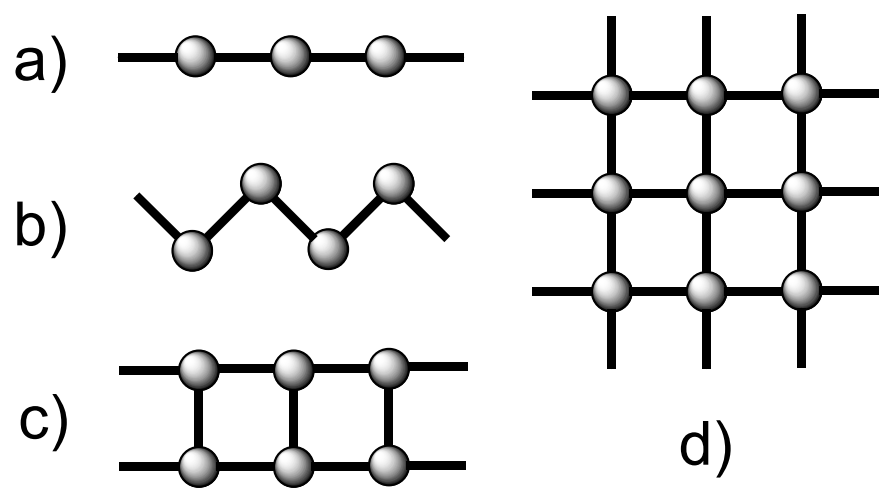

Like its lighter group homologue $\mathrm{Zn}^{2+}[15], \mathrm{Cd}^{2+}$ is particularly suited to the synthesis of coordination polymers owing to the lability that is associated with the spherical $\mathrm{d}^{10}$ electronic configuration. A search of the Cambridge Structural Database (CSD) [16] via the WebCSD interface [17] in June 2011 yielded about 250 structures containing $\mathrm{Cd}^{2+}$ bound to the 4,4'-bipy ligand. If we exclude the potentially structure-determining influence of non-solvent organic molecules [18,19] other than 4,4'-bipy, the number of coordination polymers decreases to about a dozen. These include $(4,4)$ square grid (Scheme 1(d)) [20-24] and 'T-shape' [20] 2D coordination networks, as well as linear chain (Scheme 1(a)) [19,20,25,26] and molecular antenna [19,21] 1D coordination polymers. The term molecular antenna commonly refers to a $1 \mathrm{D}$ coordination polymer with the underlying topology of the linear chain (Scheme 1(a)) bearing two additional, terminally monodentate-bound 4,4'-bipy ligands at each metal node [19,21,27-34]. Historically, Robson and co-workers were the first to report $(4,4)$ square grids with the composition $\left[\left\{\mathrm{Cd}\left(\mu-4,4^{\prime}-\text { bipy }\right)_{2}\left(\mathrm{H}_{2} \mathrm{O}\right)_{2}\right\} \mathrm{X}\right]_{\mathrm{n}}\left(\mathrm{X}=\mathrm{PF}_{6}{ }^{2-}, \mathrm{SiF}_{6}{ }^{2-}\right)$ [35]. Dinuclear 
(0D) 'H-shape' complexes of $\mathrm{Cd}^{2+}$ and 4,4'-bipy, which can be formally regarded as discrete fragments of molecular antenna polymers, have also been reported [21,36,37].

Factors such as the nature of counterions, solvents [38], metal-ligand ratio and concentrations appear to have a crucial bearing on the final outcome of reactions involving $\mathrm{Cd}^{2+}$ and $4,4^{\prime}$-bipy, but a survey of known structures reveals no simple rationalization for the structural diversity. We are only aware of one study on solid-state assembly from simple mixtures of cadmium perchlorate and 4,4'-bipy. Huang and Xiang reported the $1 \mathrm{D}$ coordination polymers $\left[\left\{\mathrm{Cd}\left(\mu-4,4^{\prime}-\right.\right.\right.$ bipy $)\left(4,4^{\prime}-\right.$ bipy $\left.\left.)_{2}\left(\mathrm{H}_{2} \mathrm{O}\right)_{2}\right\}\left(\mathrm{ClO}_{4}\right)_{2} \cdot 2 \mathrm{H}_{2} \mathrm{O}\right]_{\mathrm{n}}$ (molecular antenna) and $\left[\left\{\mathrm{Cd}\left(\mathrm{ClO}_{4}\right)_{2}(\mu-4,4 \text { '-bipy })\left(\mathrm{H}_{2} \mathrm{O}\right)_{2} \cdot 4,4^{\prime} \text { '-bipy }\right]_{\mathrm{n}}\right.$ (simple linear chain) [19]. The former was crystallized from a solution of the components in an ethanol/water mixture, whereas the latter was obtained by ethanol-thermal synthesis. A $(4,4)$ square grid constructed from $\mathrm{Cd}^{2+}$ and 4,4'-bipy, which contains perchlorate counterions, has also been reported [23]. However, this compound, $\left[\mathrm{Cd}\left(\mu-4,4^{\prime} \text {-bpy }\right)_{2}\left(\mathrm{H}_{2} \mathrm{O}\right)_{2}\right]\left(\mathrm{ClO}_{4}\right)_{2}\left(4,4^{\prime}\right.$ '-bipy $)\left(\mathrm{CH}_{3} \mathrm{OH}\right)_{2}$, was not synthesized from cadmium perchlorate but cadmium hypochlorite as the metal source. The perchlorate counterions clearly formed in situ by oxidation.

Intrigued by the rich structural chemistry of this class of compounds, we carried out further studies on supramolecular reactions of cadmium perchlorate with 4,4'-bipy. In doing so, we discovered a new example of the molecular antenna 1D coordination polymer, viz. [\{Cd( $\mu-4,4^{\prime}-$ bipy $)\left(4,4^{\prime}-\right.$ bipy $\left.)_{2}\left(\mathrm{H}_{2} \mathrm{O}\right)_{2}\right\}\left(\mathrm{ClO}_{4}\right)_{2} \cdot 2$ 4,4'-bipy $\left.\cdot 4.5 \mathrm{H}_{2} \mathrm{O}\right]_{\mathrm{n}}(\mathbf{1})$. Compound 1 was studied by single-crystal and powder X-ray diffraction (PXRD) methods, ${ }^{113} \mathrm{Cd}$ and ${ }^{13} \mathrm{C}$ solid-state NMR, as well as infrared (IR) spectroscopy. In addition, bulk material of solvent-free 4,4'-bipy and its dihydrate were subjected to ${ }^{13} \mathrm{C}$ solid-state NMR investigations.

\section{Results and Discussion}

\subsection{Synthesis}

Colorless crystals of compound 1 (Figure 1), suitable for single-crystal X-ray diffraction, were initially obtained when 4,4'-bipy and a semimolar amount of cadium perchlorate were allowed to react in an ethanol/water mixture at room temperature. Single-crystal X-ray analysis revealed a 1D coordination polymer of the molecular antenna type, as illustrated in Scheme 2. The positive charge of the cationic coordination polymer is balanced by two perchlorate ions per formula unit, and two non-coordinating 4,4'-bipy guest molecules are incorporated. A product with the same unit cell dimensions was also obtained from a mixture containing equimolar amounts of reactants. Amounts of 1 suitable for PXRD analysis and solid-state NMR investigations were obtained from a mixture with a 1:4 molar ratio (see Section 3.2). Since 1 was isolated from 1:1, 1:2 and 1:4 molar mixtures of cadmium perchlorate and 4,4'-bipy, it appears that the molecular antenna is a preferred product under various reaction conditions. Using aqueous ethanol containing significantly less water than used in this study, Huang and Xiong obtained the same molecular antenna cationic species [19] without guest 4,4'-bipy molecules in the crystal. Biradha et al. noted that the presence of excess 4,4'-bipy in transition metal coordination polymer synthesis resulted in the formation of molecular antennas [12], though this is not necessarily the case [23]. 
Figure 1. Colorless crystals (left) and PXRD patterns (right) of 1; (a) shows the experimental pattern and (b) the theoretical pattern calculated from the single-crystal data.
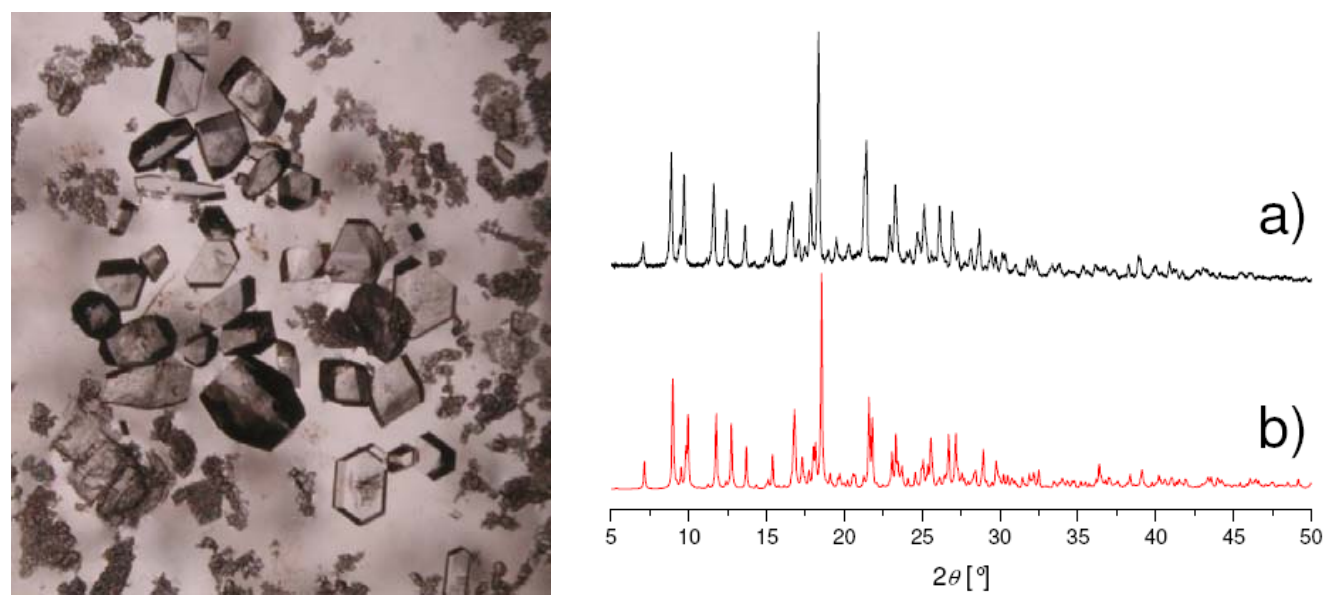

Scheme 2. Formation of the molecular coordination polymer (1) from cadmium perchlorate and 4,4'-bipy. Guest water and 4,4'-bipy molecules are omitted for clarity.

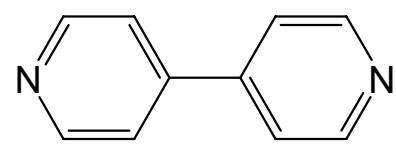

4,4'-bipy

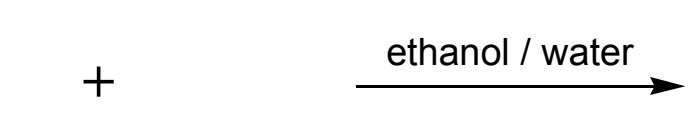

$\mathrm{Cd}\left(\mathrm{ClO}_{4}\right)_{2}$

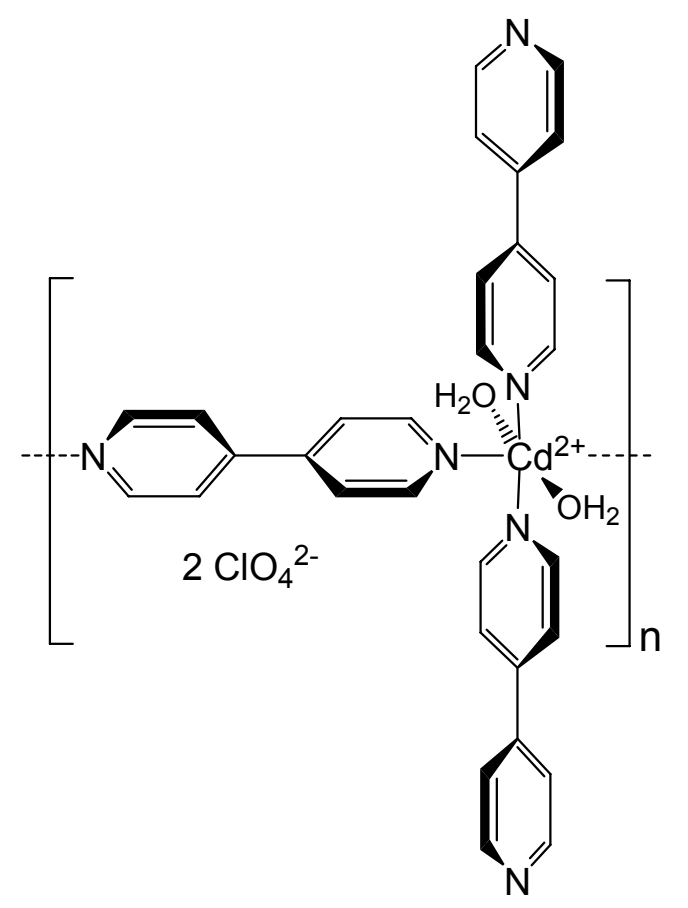

1

Besides the two non-coordinating guest 4,4'-bipy molecules, compound $\mathbf{1}$ also contains non-coordinating guest water molecules. Elemental analysis of the bulk material indicates $4.5 \mathrm{H}_{2} \mathrm{O}$ per formula unit, whereas $3.73 \mathrm{H}_{2} \mathrm{O}$ per formula unit were estimated by free refinement of the occupancies of some of the water sites during the crystal structure determination (see Section 3.3). Loss of water and/or an imperfect structural model for the severely disordered solvent regions in the crystal of $\mathbf{1}$ are possible explanations for the discrepancy. It is interesting to note that $4.5 \mathrm{H}_{2} \mathrm{O}$ per formula unit were also reported on the basis of elemental analysis for the nitrate derivative [21] of $\mathbf{1}$, the coordination polymer framework of which is isostructural to that of 1 (see Section 2.2). PXRD analysis of polycrystalline bulk material indicates that the framework structure of the single-crystal of $\mathbf{1}$ 
investigated is representative of the bulk material (Figure 1). According to ${ }^{13} \mathrm{C}$ solid-state NMR spectroscopy, there is no solvent ethanol in the structure (see Section 2.3).

Most bands in the IR spectrum can be ascribed to vibrations of 4,4'-bipy. The band centered at $621 \mathrm{~cm}^{-1}$ is tentatively assigned to the in-plane ring deformation of the pyridyl groups. This band is observed at $604 \mathrm{~cm}^{-1}$ for free pyridine and is characteristically shifted to higher frequencies upon metal coordination [39]. In compound $\mathbf{1}$, this band is expected to represent an overlap arising from coordinating and non-coordinating pyridyl groups. The strong and weak bands at respectively 1,090 and $932 \mathrm{~cm}^{-1}$ are characteristic for non-coordinating perchlorate ions [40]. The two broad and weak bands centered at 3,526 and $3,118 \mathrm{~cm}^{-1}$ are assigned to the $\mathrm{OH}$ stretching vibrations of water.

\subsection{Description of the Crystal Structure}

Figure 2 shows the structure of a single chain of the cationic molecular antenna coordination polymer in $1 . \mathrm{Cd}^{2+}$ ions are linked by 4,4 '-bipy to form a linear 1D polymeric chain via two trans coordination sites. Two terminally monodentate-bound 4,4'-bipy ligands coordinate to two trans sites in the equatorial plane of each $\mathrm{Cd}^{2+}$ node, creating the molecular antenna arrangement. Two aqua ligands in the axial positions complete the octahedral coordination sphere of $\mathrm{Cd}^{2+}$. The polymeric chain thus formed contains one crystallographically unique $\mathrm{Cd}^{2+}$ node. The repeat unit of the cationic coordination polymer is hence formulated as $\left[\mathrm{Cd}\left(\mu-4,4^{\prime} \text {-bipy }\right)\left(4,4^{\prime} \text {-bipy }\right)_{2}\left(\mathrm{H}_{2} \mathrm{O}\right)_{2}\right]^{2+}$, as illustrated in Scheme 2.

Figure 2. Part of a single chain of the cationic coordination polymer in $\mathbf{1}$, showing the relationship of the 4,4'-bipy ligands to one another in the molecular antenna coordination polymer.

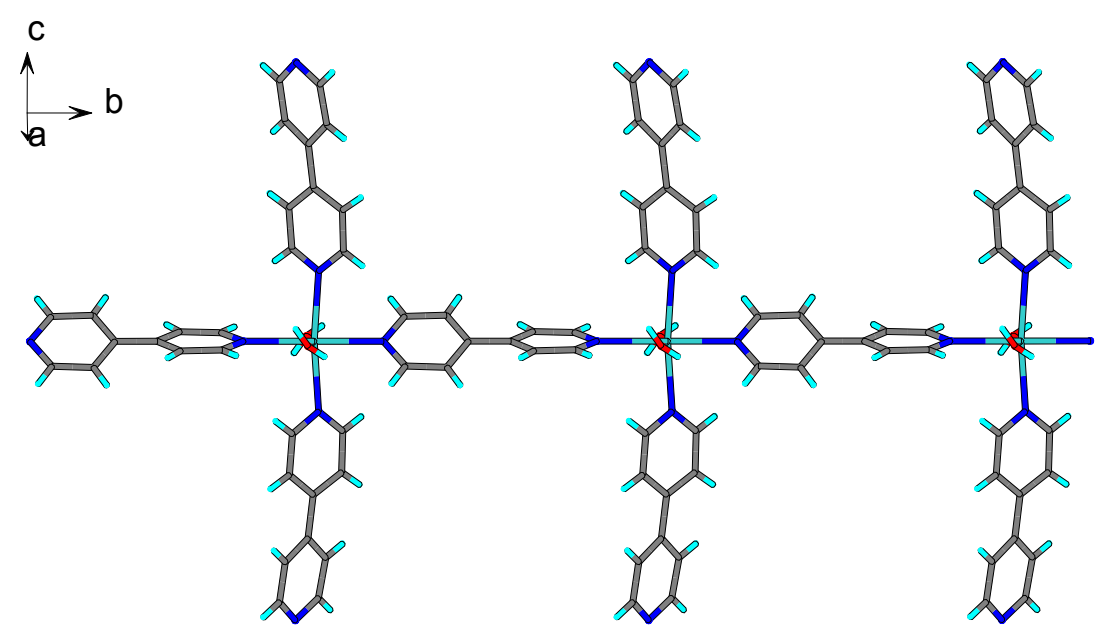

Figure 3 depicts a packing diagram. In the crystal, the polymeric chains propagate by translational symmetry parallel to the $b$ axis direction, with a period corresponding to the $b$ lattice parameter

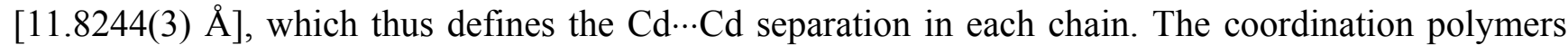
are joined together by $\mathrm{O}-\mathrm{H} \cdots \mathrm{N}$ hydrogen bonds exclusively linking aqua ligands to the $\mathrm{N}$ atoms of the non-coordinating pyridyl groups of the terminally bound 4,4'-bipy ligands in adjacent polymeric chains. The $\mathrm{O}-\mathrm{H} \cdots \mathrm{N}$ distances exhibit typical values in the range of $2.75-2.86 \AA$. These hydrogen bond 
interactions extend in the $c$ axis direction with a period of $c / 4(12.38 \AA)$. The hydrogen bond layers so formed lie parallel to the $a c$ plane and can be topologically viewed as $(4,4)$-nets [41]. Non-coordinating guest 4,4'-bipy molecules occupy the approximately rectangular voids created by the layers (Figure 3). The resulting hydrogen-bonded layers stack along the $a$ axis direction with an offset of $b / 2(5.91 \AA)$. Accommodated guest 4,4'-bipy and solvent water molecules, as well as perchlorate ions, participate in further $\mathrm{O}-\mathrm{H} \cdots \mathrm{N}$ and $\mathrm{O}-\mathrm{H} \cdots \mathrm{O}$ hydrogen bond interactions, but only between themselves and, except for the guest 4,4'-bipy molecules, via the aqua ligands of the molecular antennas.

Figure 3. Crystal structure of 1 viewed along the $a$ axis direction, showing the three independent polymeric chains (A, B, C). Unbound 4,4'-bipy molecules are shown in space filling representation. Counterions and guest water molecules are omitted for clarity.

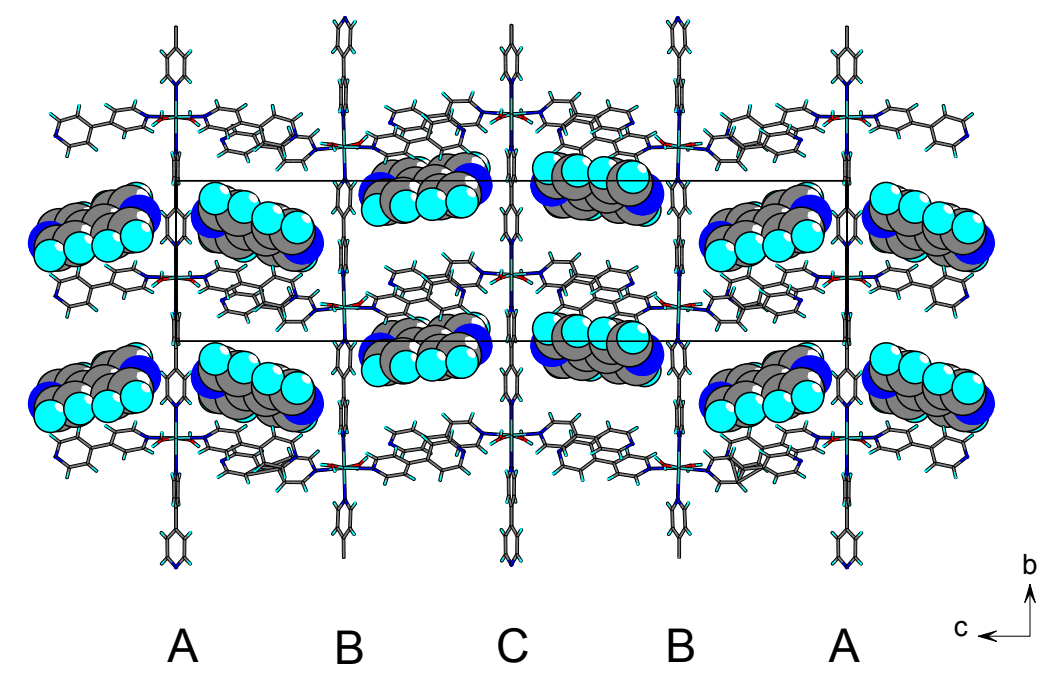

The structure of 1 contains three crystallographically independent coordination polymer strands, labeled A, B and $\mathrm{C}$ in Figure 3. Figure 4 shows the packing of polymeric chains in the monoclinic $C$-centered unit cell, viewed along the direction of propagation (i.e., the $b$ axis direction). Chains $\mathrm{A}$ and $\mathrm{C}$ run along distinct crystallographic twofold rotation axes parallel to the $b$ axis direction, and are related to one another by a pseudo translation. This additional symmetry is, however, not fulfilled by the perchlorate anions and guest molecules and is thus regarded as pseudo symmetry. Interestingly, the coordination polymer framework of $\mathbf{1}$ appears to be isostructural to that of the nitrate derivative, [\{Cd( $\mu$-4,4'-bipy)(4,4'-bipy $\left.)_{2}\left(\mathrm{H}_{2} \mathrm{O}\right)_{2}\right\}\left(\mathrm{NO}_{3}\right)_{2} \cdot 2$ 4,4'-bipy · $\left.4.5 \mathrm{H}_{2} \mathrm{O}\right]_{\mathrm{n}}(\mathrm{CSD}$ ref. code: YEKQUA) [21]. This structure has been described with the same space group symmetry and with $a$ and $b$ lattice parameters similar to those of the monoclinic unit cell of $\mathbf{1}$. The $c$ lattice parameter of YEKQUA is, however, half of that of $\mathbf{1}$. As a result, YEKQUA is a $Z^{\prime}=0.5+0.5$ structure (vide infra), as it contains two crystallographically independent polymer strands running along two distinct twofold rotation axes. In this connection, a similar unit cell and space group symmetry was found for a molecular antenna assembled from cobalt(II) nitrate and 4,4'-bipy [27]. 
Figure 4. Coordination polymer strands in the monoclinic unit cell of 1, viewed along the $b$ axis (A, green; $\mathrm{B}$, blue; $\mathrm{C}$, red). Hydrogen atoms, guest 4,4'-bipy, $\mathrm{ClO}_{4}{ }^{-}$ions and solvent water molecules are omitted for clarity.

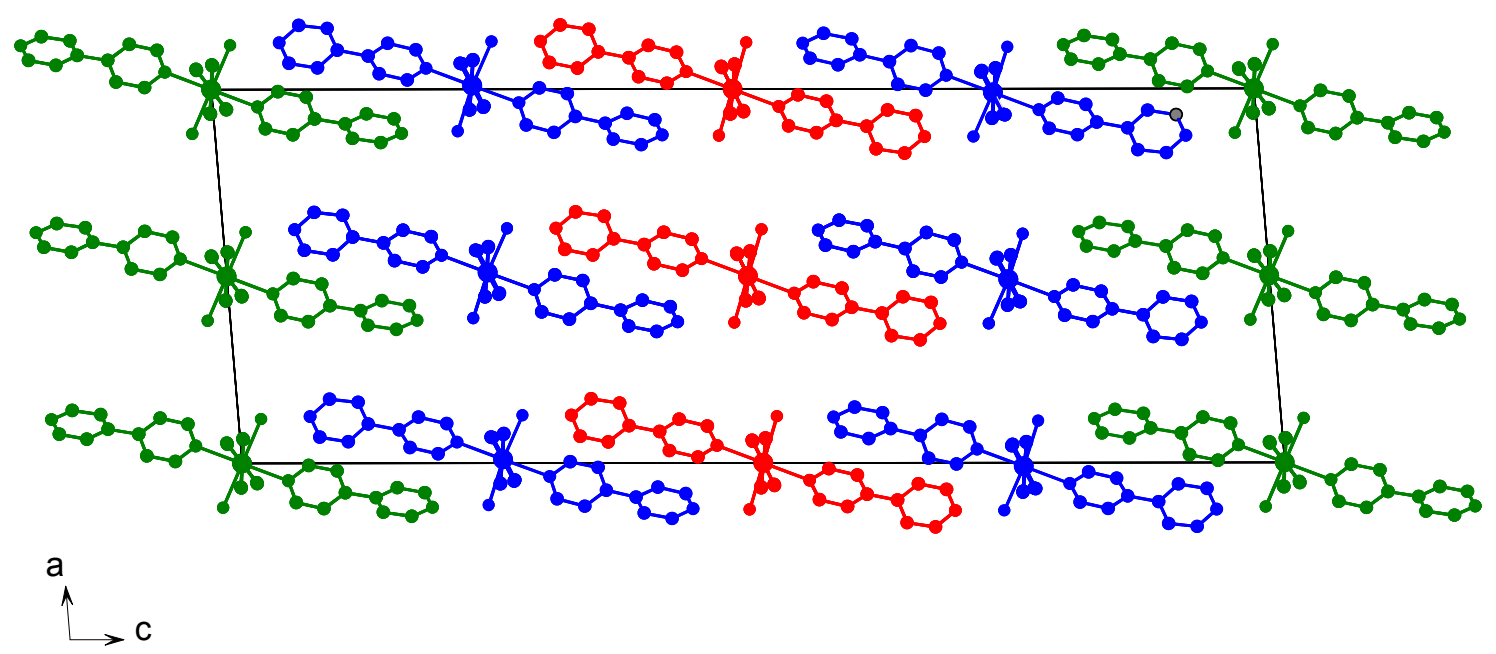

Figure 5 shows the coordination environment of the three crystallographically unique $\mathrm{Cd}^{2+}$ ions in 1, with selected bond lengths and angles given in Table 1. Cd1 occupies a general position, whereas $\mathrm{Cd} 2$ and $\mathrm{Cd} 3$ lie on two distinct crystallographic twofold rotation axes. The $\mathrm{Cd}$ coordination spheres can be described as octahedral. The bond lengths and angles about $\mathrm{Cd} 1, \mathrm{Cd} 2$ and $\mathrm{Cd} 3$ are essentially comparable, but close inspection reveals subtle differences (Table 1). The pyridyl rings adopt a more or less propeller-like configuration about each $\mathrm{Cd}^{2+}$ ion, and the 4,4'-bipy ligands exhibit the energetically preferred twisted conformation [42].

Figure 5. Section of the crystal structure of 1 showing the coordination environments of the three crystallographically independent $\mathrm{Cd}^{2+}$ ions. The labels $\mathrm{A}, \mathrm{B}$ and $\mathrm{C}$ denote the independent polymeric chain each $\mathrm{Cd}^{2+}$ ion belongs to (Figure 2). Displacement ellipsoids are drawn at the $50 \%$ probability level. Hydrogen atoms are omitted for clarity. Symmetry codes: (a) $\mathrm{x},-1+\mathrm{y}, \mathrm{z}$; (b) $-\mathrm{x}, \mathrm{y}, 1-\mathrm{z}$; (c) $-\mathrm{x}, \mathrm{y},-\mathrm{z}$; (d) $\mathrm{x}, 1+\mathrm{y}, \mathrm{z}$.

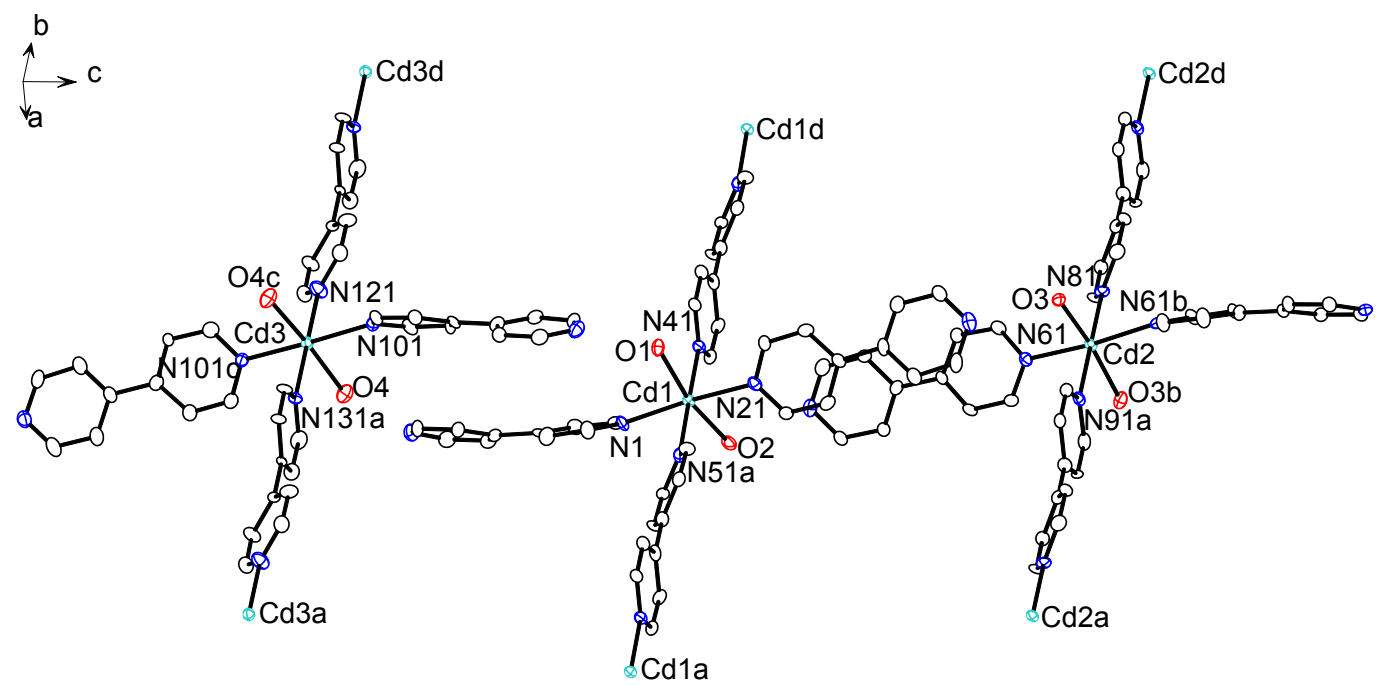


Table 1. Selected bond lengths and angles for $1\left(\AA,^{\circ}\right)$.

\begin{tabular}{llllll}
\hline Cd1-O1 & $2.280(3)$ & Cd2-O3 & $2.320(3)$ & Cd3-O4 & $2.292(4)$ \\
Cd1-O2 & $2.301(3)$ & Cd2-O3b & $2.320(3)$ & Cd3-O4c & $2.292(4)$ \\
Cd1-N1 & $2.345(4)$ & Cd2-N61 & $2.354(4)$ & Cd3-N101 & $2.348(4)$ \\
Cd1-N21 & $2.362(4)$ & Cd2-N61b & $2.354(4)$ & Cd3-N101c & $2.348(4)$ \\
Cd1-N41 & $2.391(7)$ & Cd2-N81 & $2.315(7)$ & Cd3-N121 & $2.337(8)$ \\
Cd1-N51a & $2.349(6)$ & Cd2-N91a & $2.365(9)$ & Cd3-N131a & $2.409(7)$ \\
O1-Cd1-O2 & $168.1(1)$ & O3b-Cd2-O3 & $168.5(2)$ & O4c-Cd3-O4 & $173.7(3)$ \\
O1-Cd1-N1 & $93.4(1)$ & O3-Cd2-N61 & $94.6(1)$ & O4c-Cd3-N101 & $92.6(1)$ \\
O2-Cd1-N1 & $93.7(1)$ & O3b-Cd2-N61 & $86.2(1)$ & O4-Cd3-N101 & $87.6(1)$ \\
O1-Cd1-N51a & $95.4(2)$ & O3-Cd2-N91a & $84.2(1)$ & O4c-Cd3-N131a & $86.9(1)$ \\
O2-Cd1-N51a & $94.6(2)$ & O3b-Cd2-N91a & $84.2(1)$ & O4-Cd3-N131a & $86.9(1)$ \\
N1-Cd1-N51a & $86.4(2)$ & N61b-Cd2-N91a & $93.7(1)$ & N101c-Cd3-N131a & $91.3(1)$ \\
O1-Cd1-N21 & $87.4(1)$ & O3-Cd2-N61b & $86.2(1)$ & O4c-Cd3-N101 & $92.6(1)$ \\
O2-Cd1-N21 & $86.5(1)$ & O3b-Cd2-N61b & $94.6(1)$ & O4-Cd3-N101 & $87.6(1)$ \\
N1-Cd1-N21 & $174.0(2)$ & N61b-Cd2-N61 & $172.7(2)$ & N101-Cd3-N101c & $177.4(3)$ \\
N51a-Cd1-N21 & $87.6(2)$ & N61b-Cd2-N91a & $93.7(1)$ & N101-Cd3-N131a & $91.3(1)$ \\
O1-Cd1-N41 & $86.1(1)$ & N81-Cd2-O3 & $95.8(1)$ & O4c-Cd3-N121 & $93.1(1)$ \\
O2-Cd1-N41 & $84.0(1)$ & N81-Cd2-O3b & $95.8(1)$ & O4-Cd3-N121 & $93.1(1)$ \\
N1-Cd1-N41 & $93.4(2)$ & N81-Cd2-N61 & $86.3(1)$ & N121-Cd3-N101c & $88.7(1)$ \\
N51a-Cd1-N41 & $178.5(1)$ & N81-Cd2-N91a & 180.0 & N121-Cd3-N131a & 180.0 \\
N21-Cd1-N41 & $92.6(2)$ & N81-Cd2-N61b & $86.3(1)$ & N121-Cd3-N101 & $88.7(1)$ \\
\hline
\end{tabular}

We suggest that a $Z^{\prime}=2$ value is appropriate for the crystal structure of 1 . The parameter $Z^{\prime}$ conventionally denotes the number of formula units in the asymmetric unit [43]. This implies that $Z$ ' crucially depends on the definition of the formula unit. The problem becomes particularly apparent when polymeric structures are described [44]. As discussed in Section 2.2, the repeat unit of the three chemically identical but crystallographically distinct polymeric chains in $\mathbf{1}$ is best described by the chemical formula $\left[\mathrm{Cd}(\mu-4,4 \text { '-bipy })(4,4 \text { '-bipy })_{2}\left(\mathrm{H}_{2} \mathrm{O}\right)_{2}\right]^{2+}$. The asymmetric unit of 1 contains one entire and two independent halves of the formula unit, resulting in $Z^{\prime}=1+0.5+0.5$. Structures such as 1 illustrate the inability of the $Z$ ' parameter to adequately describe all aspects of the crystal packing where Z' $>1$ [45]. Possible reasons for the formation of Z'>1 structures, e.g., packing difficulties and pseudo symmetry, have been discussed in the literature $[45,46]$. Considering that twisted biphenyl derivatives are prone to form such structures [45], the occurrence of three crystallographically distinct polymeric chains in $\mathbf{1}$ is not particularly surprising. It is perhaps worth noting that both free 4,4'-bipy [47] and its dihydrate [48] crystallize with two independent, twisted molecules in the asymmetric unit.

\section{3. ${ }^{113} \mathrm{Cd}$ and ${ }^{13} \mathrm{C}$ Solid-State NMR Spectroscopy}

A solid-state ${ }^{113} \mathrm{Cd} \mathrm{NMR}$ analysis of $\mathbf{1}$ was undertaken in order to gain more insight into the differences in the local environments of the three crystallographically distinct $\mathrm{Cd}$ atoms in the crystal structure, shown in Figure 5. Interestingly, the ${ }^{113} \mathrm{Cd}$ MAS NMR spectra, recorded with and without cross-polarization, show a single line at 89 ppm (fwhh: $c a .620 \mathrm{~Hz}$ ), with weak side bands at medium 
spinning rates (Figure 6). Clearly, the resolution is insufficient to resolve the independent $\mathrm{Cd}$ atoms in the crystal, consistent with the similarity of the local environments of the three independent $\mathrm{Cd}$ atoms in the structure. The lack of strong spinning side bands suggests that the anisotropy of the chemical shift is small. Reducing the spinning rate to $3 \mathrm{kHz}$ (Figure 6(c)) resulted in the appearance of intense spinning side bands. The spectrum recorded without spinning shows that the span caused by chemical shift anisotropy in $\mathbf{1}$ is only about 100 ppm, which is surprisingly small, especially since the coordination sphere of Cd contains four nitrogen and two oxygen atoms. Lipton et al., for example, observed multiple side bands for $\mathrm{N}_{6}$ coordination environments, due to a three times larger anisotropy [49]. The chemical shift for 1 lies in the region expected for octahedral coordination complexes with oxygen or nitrogen ligands coordinated to the metal [50].

Figure 6. Solid-state ${ }^{113} \mathrm{Cd}$ NMR spectra of 1: (a) Bloch decay spectrum at $7 \mathrm{kHz}$ MAS frequency, (b) $\mathrm{CP} / \mathrm{MAS}$ spectrum at $10 \mathrm{kHz}$, (c) $\mathrm{CP} / \mathrm{MAS}$ spectrum at $3 \mathrm{kHz}$, (d) $\mathrm{CP}$ spectrum of the stationary sample. Spectra arranged from bottom to top for clarity.

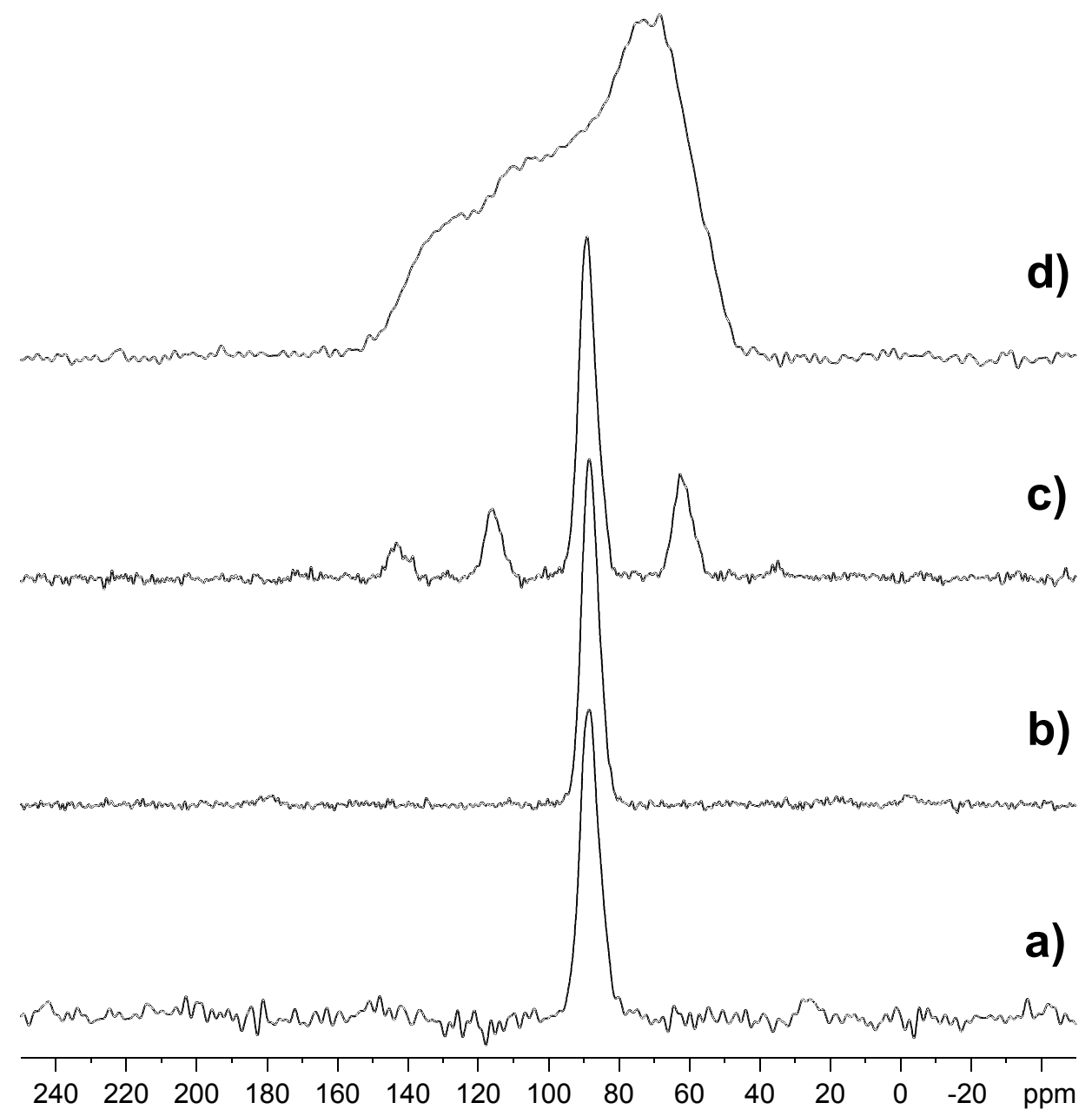

The solid-state ${ }^{13} \mathrm{C}$ NMR spectrum of $\mathbf{1}$ is shown in Figure 7(a). As expected, the spectrum exhibits three groups of lines, which are assigned according to Osborne [51] (solution NMR) and Braga et al. [52] (solid-state NMR). The spectrum of 4,4'-bipy in $\mathbf{1}$ is well-resolved, in stark contrast to that obtained for co-crystals containing 4,4'-bipy [52], pure solid anhydrous 4,4'-bipy (Figure 7(b)) and 4,4'-bipy dihydrate (Figure 7(c)). The ill-resolved lines observed for pure solid anhydrous 4,4'-bipy and 4,4'-bipy 
dihydrate cannot be due to the formation of amorphous phases, since samples from the same batches were shown to be crystalline by independent PXRD and single-crystal diffraction investigations. It is noteworthy that the aliphatic region of the spectrum shows no signal that could be attributed to ethanol guest molecules, ruling out the presence of ethanol in the disordered regions of the crystal (see Sections 2.1 and 3.1). Although actual assignment of the fine structure in the ${ }^{13} \mathrm{C}$ solid-state NMR spectrum of 1 was not possible due to the lack of examples suitable for comparison, it is surprising that the lines are remarkably well-resolved in the $\mathrm{Cd}^{2+}$ coordination polymer. The influence of the coordinating $\mathrm{Cd}$ atom on the ${ }^{13} \mathrm{C}$ chemical shifts of the 4,4'-bipy ligands is remarkable. Studies on simple 4,4'-bipy $\mathrm{Cd}^{2+}$ complexes containing, for example, one independent molecule in the asymmetric unit would be useful to shed light on this interesting phenomenon.

Figure 7. ${ }^{13} \mathrm{C} \mathrm{CP/MAS} \mathrm{NMR} \mathrm{spectra} \mathrm{of} 1$ (a), anhydrous 4,4'-bipy (480 s recycle delay) (b) and 4,4'-bipy dihydrate (30 s recycle delay) (c).

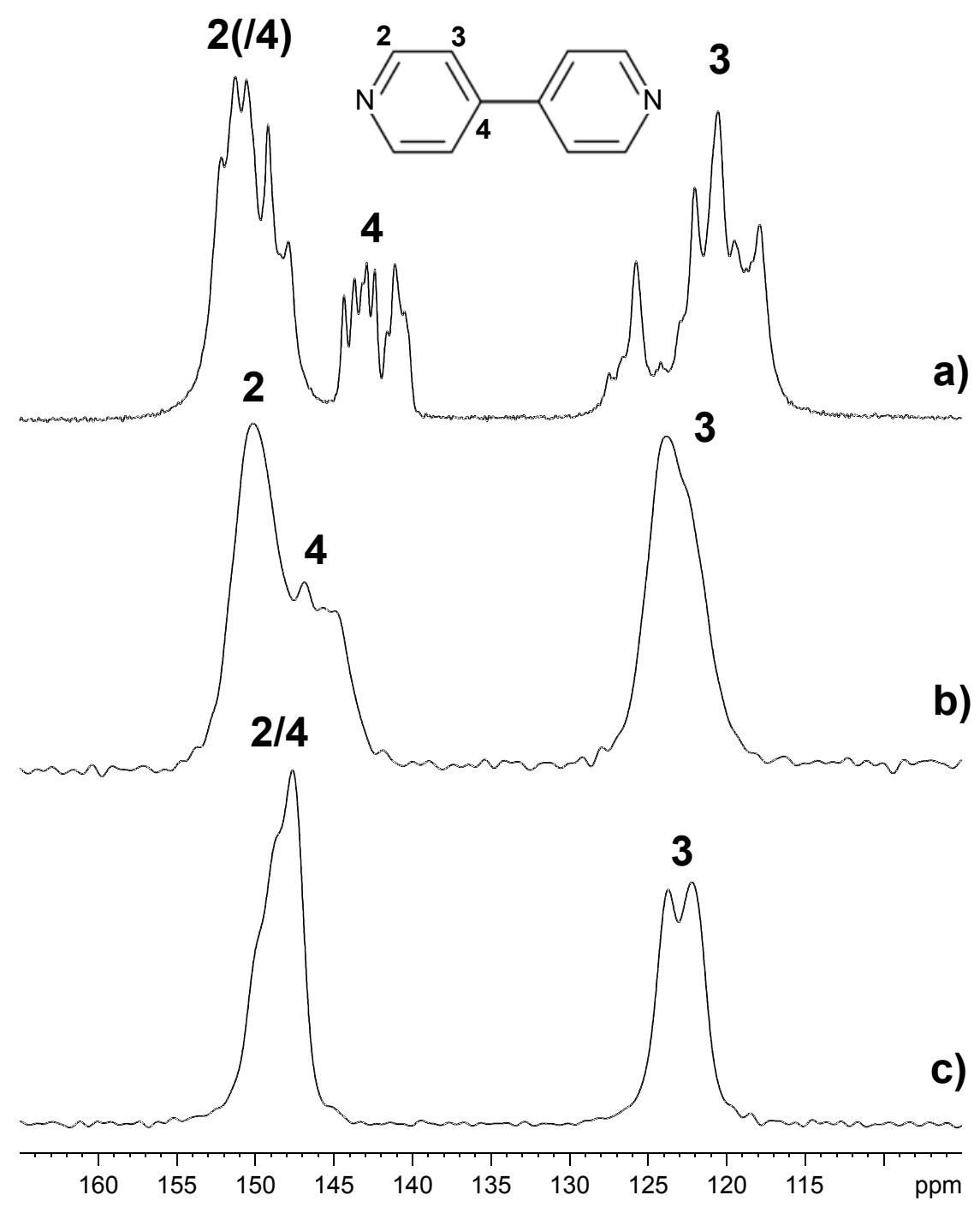




\section{Experimental Section}

\subsection{General}

All starting materials were obtained from commercial sources and used as received. Ethanol was of reagent grade. The IR spectrum was recorded in the range of 4,000-600 $\mathrm{cm}^{-1}$ on a Bruker Tensor 27 FT-IR spectrometer by using ATR technique. Elemental analysis was carried out at Mikroanalytisches Laboratorium KOLBE in Mülheim an der Ruhr, Germany. Caution: perchlorate salts are potentially explosive and should be handled with great care.

\subsection{Preparation of 1}

$\mathrm{Cd}\left(\mathrm{ClO}_{4}\right)_{2} \cdot 6 \mathrm{H}_{2} \mathrm{O}(105 \mathrm{mg}, 0.25 \mathrm{mmol})$ was dissolved in deionized water $(20 \mathrm{~mL})$ and carefully layered with a solution of 4,4'-bipy $\cdot 2 \mathrm{H}_{2} \mathrm{O}(192 \mathrm{mg}, 1.00 \mathrm{mmol})$ in $10 \mathrm{~mL}$ of ethanol. After standing at room temperature for $c a$. four weeks, while the solvent was allowed to evaporate slowly, colorless crystalline material of 1 was collected and dried on a filter paper. Yield: $128 \mathrm{mg}(0.11 \mathrm{mmol}, 55 \%$ based on 4,4'-bipy - $2 \mathrm{H} 2 \mathrm{O}$ ). Anal. calcd. for $\mathrm{C}_{50} \mathrm{H}_{53} \mathrm{Cl}_{2} \mathrm{~N}_{10} \mathrm{O}_{14.5} \mathrm{Cd}$ : C: 49.7; $\mathrm{H}: 4.4$; $\mathrm{N}: 11.6 \%$. Found: C: 49.6; H: 4.3; N: 11.4\%. IR: 3526(w), 3118(w), 1599(m), 1535(m), 1489(w), 1408(m), 1323(w), 1221(m), 1090(s), 1061(s), 1003(m), 932(w), 872(w), 860(w), 849(w), 814(m), 800(s), 729(m), 621(s) $\mathrm{cm}^{-1}$.

\subsection{Single-Crystal X-Ray Analysis}

A crystal was mounted on a MiTeGen cryo loop using perfluoropolyether Fomblin YR-1800 (Alfa Aesar) and placed in the nitrogen cold-gas stream of the diffractometer. The intensity data were measured on a Bruker AXS Proteum X8 diffractometer equipped with a FR591 rotating anode and focusing multilayer optics, using $\omega$ and $\phi$ scans. The PROTEUM2 software was used to control the diffractometer [53]. The raw frame data were integrated with the program SAINT [54]. Scaling and an absorption correction were carried out by Gaussian integration using SADABS [55]. The crystal structure was solved $a b$ initio by charge flipping using SUPERFLIP [56]. The electron density map so obtained was interpreted with EDMA [57]. The structural model was completed by difference Fourier syntheses and refined by full-matrix least-squares refinement on $F^{2}$ with SHELXL-97 [58]. The crystal of 1 studied appeared to be a racemic twin. Refinement of the twin components converged at 0.501(5):0.499(5). Anisotropic displacement parameters were introduced for all non-hydrogen atoms with the exception of some solvent water molecules (vide infra). Two of the perchlorate anions each show orientational disorder over two positions. Split models were introduced for both disordered groups and refined with standard similar distance restraints. The highest difference electron density peak is located ca. $0.94 \AA$ from Cd1. Carbon-bound hydrogen atoms were placed at geometrically calculated positions and refined with the appropriate riding model. The water hydrogen atoms were located via difference Fourier syntheses and refined with the $\mathrm{O}-\mathrm{H}$ distances restrained to a target value of $0.84(2) \AA$. All hydrogen atoms were refined with $U_{\text {iso }}(\mathrm{H})=1.2 U_{\text {eq }}(\mathrm{C}, \mathrm{O})$. Six water sites are statistically occupied; the site occupancy factors were refined freely. Three of these six water sites were refined with isotropic atomic displacement parameters for the oxygen atoms. The hydrogen atoms of the six statistically occupied water sites could not be located in the final difference map, and 
where not included in the refinement. Calculated intermolecular $\mathrm{O} \cdots \mathrm{O}$ distances indicate that not all of the disordered perchlorate anion and water sites can be occupied simultaneously. The ADDSYM routine of PLATON [59] detects additional translational symmetry in the coordination polymer framework, which is in fact pseudo symmetry (see Section 2.2). Crystal data and refinement details are given in Table 2. CCDC 836453 contains the supplementary crystallographic data for this paper, including structure factors. These data can be obtained free of charge from the Cambridge Crystallographic Data Centre via www.ccdc.cam.ac.uk/data_request/cif.

Table 2. Crystal data and refinement details for $\mathbf{1}$.

\begin{tabular}{|c|c|}
\hline empirical formula & $\mathrm{C}_{50} \mathrm{H}_{51.46} \mathrm{Cl}_{2} \mathrm{~N}_{10} \mathrm{O}_{13.73} \mathrm{Cd}$ \\
\hline$M_{\mathrm{r}}\left(\mathrm{g} \mathrm{mol}^{-1}\right)$ & $1,195.45$ \\
\hline$\lambda(\AA)$ & 1.54178 \\
\hline crystal size $\left(\mathrm{mm}^{3}\right)$ & $0.34 \times 0.17 \times 0.14$ \\
\hline crystal system & monoclinic \\
\hline space group & $C 2$ \\
\hline$T(\mathrm{~K})$ & $100(2)$ \\
\hline$a(\AA)$ & $17.8198(5)$ \\
\hline$b(\AA)$ & $11.8244(3)$ \\
\hline$c(\AA)$ & $49.525(1)$ \\
\hline$\beta\left(^{\circ}\right)$ & $94.655(1)$ \\
\hline$V\left(\AA^{3}\right)$ & $10,401.0(5)$ \\
\hline$Z, Z$ & 8,2 \\
\hline$\rho_{\text {calc }}\left(\mathrm{g} \mathrm{cm}^{-3}\right)$ & 1.527 \\
\hline$\mu\left(\mathrm{mm}^{-1}\right)$ & 4.954 \\
\hline $2 \theta_{\max }\left({ }^{\circ}\right)$ & 133.38 \\
\hline reflections collected/unique & $11,7435 / 17,707$ \\
\hline$R_{\text {int }}$ & 0.0418 \\
\hline observed data $[I>2 \sigma(I)]$ & 17,572 \\
\hline Goodness-of-fit on $F^{2}$ & 1.024 \\
\hline refined parameters/restraints & $1,518 / 247$ \\
\hline$R_{1}[I>2 \sigma(I)]$ & 0.0376 \\
\hline$w R_{2}($ all data $)$ & 0.1087 \\
\hline residuals $\left(\mathrm{e} \AA^{-3}\right)$ & $0.91 /-0.97$ \\
\hline
\end{tabular}

\subsection{Powder X-Ray Diffraction}

The PXRD data for bulk material of compound $\mathbf{1}$ were collected at room temperature in Debye-Scherrer geometry on a Stoe Stadi P system with a linear position sensitive detector and a focused $\mathrm{Cu}-\mathrm{K}_{\alpha 1}(\lambda=1.54060 \AA)$ incident beam from a curved Ge(111) monochromator. The capillary sample (inner diameter $=0.5 \mathrm{~mm}$ ) was rotated during the measurement. The WinXPOW software was used to operate the diffractometer [60]. The theoretical PXRD pattern of 1 was calculated from the single-crystal data with Mercury 2.4 [61]. 


\subsection{Solid-State NMR Spectroscopy}

The solid-state NMR spectra were recorded on a Bruker Avance 500WB spectrometer using a double-bearing standard MAS probe (DVT BL4) at resonance frequencies of $110.9 \mathrm{MHz}$ and $125.8 \mathrm{MHz}$

for ${ }^{113} \mathrm{Cd}$ and ${ }^{13} \mathrm{C}$, respectively. Polycrystalline samples $(c a .100 \mathrm{mg}$ ), containing naturally abundant ${ }^{113} \mathrm{Cd}$ and ${ }^{13} \mathrm{C}$, were placed in a zirconia rotor. The experimental conditions for the ${ }^{113} \mathrm{Cd}$ and ${ }^{13} \mathrm{C} \mathrm{CP}$ MAS NMR spectra were as follows: up to $10 \mathrm{kHz}$ spinning rate, $8 \mathrm{~s}$ recycle delay, between 2,000 and 20,000 scans, $4 \mathrm{~ms}$ contact time, and $4.3 \mu \mathrm{s}{ }^{1} \mathrm{H} \pi / 2$ pulse. Longer recycle delays were used for recording the ${ }^{13} \mathrm{C} \mathrm{CP} / \mathrm{MAS} N \mathrm{NMR}$ spectra of anhydrous $4,4^{\prime}$-bipy and 4,4'-bipy dihydrate. The ${ }^{113} \mathrm{Cd}$ MAS NMR spectra were measured using single $\pi / 3$-pulses $(3 \mu \mathrm{s})$ with a recycle delay of $30 \mathrm{~s}$ (2,000-8,000 scans). High-power proton decoupling (cw) was applied for all spectra. The chemical shift was referenced to $1 \mathrm{M}$ aqueous solution of $\mathrm{Cd}\left(\mathrm{ClO}_{4}\right)_{2}$ and neat TMS in separate rotors for ${ }^{113} \mathrm{Cd}$ and ${ }^{13} \mathrm{C}$, respectively.

\section{Conclusions}

We have obtained a $1 \mathrm{D}$ coordination polymer with a molecular antenna structure by layering a solution of 4,4'-bipy in ethanol onto an aqueous solution of cadmium perchlorate. The compound (1) has been structurally characterized by X-ray diffraction methods, solid-state NMR and IR spectroscopy. Several observations are relevant in the context of crystal engineering: (a) the bulk material was shown to be homogeneous, with no measurable crystalline impurities; (b) the same compound was isolated from various molar ratios of cadmium perchlorate and 4,4'-bipy, indicating that the molecular antenna is a preferred product; (c) there was no incorporation of ethanol in the sample, although it was present in the reaction solution; (d) the aqua ligands in the coordination polymer only make $\mathrm{O}-\mathrm{H} \cdots \mathrm{N}$ hydrogen bonds to the uncoordinated $\mathrm{N}$ atoms of coordinated 4,4'-bipy ligands in neighboring strands, even though unbound, guest 4,4'-bipy molecules are clearly available for hydrogen bonding.

According to the single crystal and PXRD studies on the bulk material, $\mathbf{1}$ crystallizes exclusively in a unit cell containing three distinct strands. ${ }^{113} \mathrm{Cd}$ MAS NMR spectra recorded with and without cross-polarization exhibit a single line, showing that the individual lines are not resolved because the local environments are very similar. The difference between the three strands can be attributed to the conformations adopted by the 4,4'-bipy ligands. We observed an increased resolution in the solid-state ${ }^{13} \mathrm{C}$ NMR spectrum of $\mathbf{1}$ as compared to the spectra of pure crystalline 4,4'-bipy and 4,4'-bipy dihdrate. This phenomenon deserves further investigation.

\section{Acknowledgements}

R.W.S. would like to thank William S. Sheldrick and Christian W. Lehmann for their generous support. Claudia Weidenthaler (Max-Planck-Institut für Kohlenforschung, Department of Hetero-geneous Catalysis) and Jan Dittrich (Ruhr-Universität Bochum, Department of Inorganic Chemistry) are acknowledged for technical assistance with the PXRD analysis and IR spectroscopy, respectively. 


\section{References}

1. Robin, A.Y.; Fromm, K.M. Coordination polymer networks with O- and N-donors: What they are, why and how they are made. Coord. Chem. Rev. 2006, 250, 2127-2157.

2. Hong, M. Inorganic-organic hybrid coordination polymers: A new frontier for materials research. Cryst. Growth Des. 2007, 7, 10-14.

3. Kawano, M.; Fujita, M. Direct observation of crystalline-state guest exchange in coordination networks. Coord. Chem. Rev. 2007, 251, 2592-2605.

4. Horike, S.; Shimomura, S.; Kitagawa, S. Soft porous crystals. Nat. Chem. 2009, 1, 695-704.

5. Shimomura, S.; Bureekaew, S.; Kitagawa, S. Porous coordination polymers towards gas technology. Struct. Bond. 2009, 132, 51-86.

6. Noro, S.-I.; Kitagawa, S.; Akutagawa, T.; Nakamura, T. Coordination polymers constructed from transition metal ions and organic N-containing heterocyclic ligands: Crystal structures and microporous properties. Prog. Polym. Sci. 2009, 34, 240-279.

7. Kuppler, R.J.; Timmons, D.J.; Fang, Q.-R.; Lia, J.-R.; Makala, T.A.; Young, M.D.; Yuan, D.; Zhao, D.; Zhuang, W.; Zhou, H.-C. Potential applications of metal-organic frameworks. Coord. Chem. Rev. 2009, 253, 3042-3066.

8. Farrusseng, D.; Aguado, S.; Pinel, C. Metal-organic frameworks: Opportunities for catalysis. Angew. Chem. Int. Ed. 2009, 48, 7502-7513.

9. Perry, J.J., IV; Perman, J.A.; Zaworotko, M.J. Design and synthesis of metal-organic frameworks using metal-organic polyhedra as supermolecular building blocks. Chem. Soc. Rev. 2009, 38, 1400-1417.

10. Janiak, C.; Vieth, J.K. MOFs, MILs and more: Concepts, properties and applications for porous coordination networks (PCNs). New J. Chem. 2010, 34, 2366-2388.

11. Liu, T.-F.; Lü, J.; Cao, R. Coordination polymers based on flexible ditopic carboxylate or nitrogen-donor ligands. CrystEngComm 2010, 12, 660-670.

12. Biradha, K.; Sarkar, M.; Rajput, L. Crystal engineering of coordination polymers using 4,4'-bipyridine as a bond between transition metal atoms. Chem. Commun. 2006, 4169-4179.

13. Gable, R.W.; Hoskins, B.F.; Robson, R. A new type of interpenetration involving enmeshed independent square grid sheets. The structure of diaquabis-(4,4'-bipyridine)zinc hexafluorosilicate. J. Chem. Soc. Chem. Commun. 1990, 1677-1678.

14. Fujita, M.; Yazaki, J.; Ogura, K. Preparation of a macrocyclic polynuclear complex, [(en)Pd(4,4'bpy) $]_{4}\left(\mathrm{NO}_{3}\right)_{8}$, which recognizes an organic molecule in aqueous media. J. Am. Chem. Soc. 1990, $112,5645-5648$.

15. Erxleben, A. Structures and properties of $\mathrm{Zn}(\mathrm{II})$ coordination polymers. Coord. Chem. Rev. 2003, 246, 203-228.

16. Groom, C.R.; Allen, F.H. The Cambridge Structural Database: Experimental three-dimensional information on small molecules is a vital resource for interdisciplinary research and learning. WIREs Comput. Mol. Sci. 2011, 1, 368-376.

17. Thomas, I.R.; Bruno, I.J.; Cole, J.C.; Macrae, C.F.; Pidcock, E.; Wood, P.A. WebCSD: The online portal to the Cambridge Structural Database. J. Appl. Cryst. 2010, 43, 362-366. 
18. Fujita, M.; Kwon, Y.J.; Washizu, S.; Ogura, K. Preparation, clathration ability, and catalysis of a two-dimensional square network material composed of Cadmium(II) and 4,4'-bipyridine. J. Am. Chem. Soc. 1994, 116, 1151-1152.

19. Huang, S.D.; Xiong, R.-G. Molecular recognition of organic chromosphores by coordination polymers: Design and construction of nonlinear optical supramolecular assemblies. Polyhedron 1997, 16, 3929-3939.

20. Sampanthar, J.T.; Vittal, J.J. Reaction of $\mathrm{Cd}\left(\mathrm{NO}_{3}\right)_{2} \cdot 4 \mathrm{H}_{2} \mathrm{O}$ with 4,4 '-bipyridine (bpy) in $\mathrm{MeOH}$ solvent: Synthesis and characterization of T-shaped $\left[\mathrm{Cd}(\mathrm{bpy})_{1.5}\left(\mathrm{NO}_{3}\right)_{2}\right] \cdot 3 \mathrm{H}_{2} \mathrm{O}$, square grid $\left[\mathrm{Cd}(\text { bpy })_{2}\left(\mathrm{H}_{2} \mathrm{O}\right)_{2}\right]\left(\mathrm{NO}_{3}\right) \cdot 2 \cdot 4 \mathrm{H}_{2} \mathrm{O}$ and linear polymeric $\left[\mathrm{Cd}(\right.$ bpy $\left.)\left(\mathrm{H}_{2} \mathrm{O}\right)_{2}\left(\mathrm{NO}_{3}\right)_{2}\right]$. Cryst. Eng. 1999, 2, 251-264.

21. Aoyagi, M.; Biradha, K.; Fujita, M. Formation of two, one, and zero-dimensional coordination assemblies from Cd(II) ion and 4,4'-bipyridine. Bull. Chem. Soc. Jpn. 2000, 73, 1369-1373.

22. Tong, M.-L.; Zheng, S.-L.; Chen, X.-M. Synthesis and structures of two-dimensional coordination polymers constructed by metal salts and 4,4'-bipyridine. Polyhedron 2000, 19, 1809-1814.

23. Jiang, J.-J.; Liu, Y.-R.; Yang, R.; Pan, M.; Cao, R.; Su, C.-Y. The interplay of coordinative and hydrogen-bonding in directing the $\left[\mathrm{M}\left(4,4^{\prime}-\mathrm{bpy}\right)_{2}\left(\mathrm{H}_{2} \mathrm{O}\right)_{2}\right]$ square-grid networks: Formation of 3D porous framework $\left[\mathrm{Cd}\left(4,4^{\prime} \text {-bpy }\right)_{2}\left(\mathrm{H}_{2} \mathrm{O}\right)_{2}\right]\left(\mathrm{ClO}_{4}\right)_{2}(4,4$ '-bpy $)\left(\mathrm{CH}_{3} \mathrm{OH}\right)_{2}$. CrystEngComm 2008, 10, 1147-1153.

24. Cui, X.; Khlobystov, A.N.; Chen, X.; Marsh, D.H.; Blake, A.J.; Lewis, W.; Champness, N.R.; Roberts, C.J.; Schröder, M. Dynamic equilibria in solvent-mediated anion, cation and ligand exchange in transition-metal coordination polymers: Solid-state transfer or recrystallisation? Chem. Eur. J. 2009, 15, 8861-8873.

25. Xiong, R.-G.; Liu, C.-M.; Zuo, J.-L.; You, X.-Z. Guest-induced dimension change. A novel network intercalation complex: $\left\{\left[\mathrm{Cd}\left(4,4^{\prime}-\text { bipy }\right)_{2}\left(\mathrm{H}_{2} \mathrm{O}\right)_{2}\right]\left(\mathrm{CF}_{3} \mathrm{SO}_{3}\right) 2\left(4,4^{\prime}-\text { bipy }\right)\left(\mathrm{H}_{2} \mathrm{O}\right)_{2}\left(\mathrm{C}_{7} \mathrm{H}_{8} \mathrm{~N}_{2} \mathrm{O}_{3}\right)_{2}\right\}_{\infty}$. Inorg. Chem. Commun. 1999, 2, 292-297.

26. Croitor, L.; Coropceanu, E.B.; Jeanneau, E.; Dementiev, I.V.; Goglidze, T.I.; Chumakov, Y.M.; Fonari, M.S. Anion-induced generation of binuclear and polymeric $\mathrm{Cd}(\mathrm{II})$ and $\mathrm{Zn}(\mathrm{II})$ coordination compounds with 4,4'-bipyridine and dioxime ligands. Cryst. Growth Des. 2009, 9, 5233-5243.

27. Felloni, M.; Blake, A.J.; Champness, N.R.; Hubberstey, P.; Wilson, C.; Schröder, M. Supramolecular interactions in 4,4'-bipyridine Cobalt(II) nitrate networks. J. Supramol. Chem. 2002, 2, 163-174.

28. Woodward, J.D.; Backov, R.; Abboud, K.A.; Ohnuki, H.; Meisel, M.W.; Talham, D.R. Structural, thermal, and magnetic properties of three transition metal-4,4'-bipyridine coordination polymers: $\left[\mathrm{Ni}(4,4 \text { '-bipy })_{3}\left(\mathrm{H}_{2} \mathrm{O}\right) 2\right]\left(\mathrm{ClO}_{4}\right)_{2} \cdot 1.4(4,4$ '-bipy $) \cdot 3\left(\mathrm{H}_{2} \mathrm{O}\right)$; $\left[\mathrm{Co}(4,4 \text { '-bipy })_{3}\left(\mathrm{H}_{2} \mathrm{O}\right)_{2}\right]\left(\mathrm{ClO}_{4}\right)_{2} \cdot 1,4(4,4$ 'bipy)·3( $\left.\mathrm{H}_{2} \mathrm{O}\right)$; [Cu(4,4'-bipy $\left.)_{3}(\mathrm{dmso})_{2}\right]\left(\mathrm{ClO}_{4}\right)_{2} \cdot 2$ (4,4'-bipy). Polyhedron 2003, 22, 2821-2830.

29. Zhu, L.-N.; Wang, Q.-L.; Wang, W.-Z.; Liao, D.-Z.; Jianga, Z.-H.; Yan, S.-P. Topological control in coordination polymers by solvent: The synthesis and structure of a novel 1D coordination polymer $\left\{\left[\mathrm{Co}\left(\mu-4,4^{\prime} \text { 'bpy }\right)\left(4,4^{\prime} \text { '-bpy }\right)_{2}(\mathrm{NCS})_{2}\right] \cdot 2 \mathrm{DMF}\right\}_{\mathrm{n}}$. J. Mol. Struct. 2003, 649, 111-115.

30. Izarova, N.V.; Sokolova, M.N.; Rothenberger, A.; Ponikiewski, L.; Fenske, D.; Fedin, V.P. Synthesis and crystal structure of a new metal-organic coordination polymer $\left[\mathrm{Fe}(4,4 \text { '-bpy })_{3}\left(\mathrm{H}_{2} \mathrm{O}\right)_{2}\right]\left(\mathrm{PF}_{6}\right) 2 \cdot 2(4,4$ '-bpy $) \cdot 5 \mathrm{H}_{2} \mathrm{O}$ with nanosized channels clathrate large organic molecules. C. R. Chim. 2005, 8, 1005-1010. 
31. Woodward, J.D.; Backov, R.V.; Abbouda, K.A.; Talham, D.R. Monomers, chains, ladders, and two-dimensional sheets: Structural diversity in six new compounds of Zn(II) with 4,4'-bipyridine. Polyhedron 2006, 25, 2605-2615.

32. Jin, J.; Niu, S.Y.; Yang, G.D.; Ye, L. Hydrothermal synthesis, structural characterization, magnetic and photoelectric properties of two Cobalt(II) coordination polymers. Z. Anorg. Allg. Chem. 2006, 632, 2350-2354.

33. Luachan, S.; Pakawatchai, C.; Rujiwatra, A. Hydrothermal crystal growth, structures and thermal properties of $\mathrm{Co}(\mathrm{II})-4,4$ '-bipyridine-based coordination polymeric materials. J. Inorg. Organomet. Polym. Mater. 2007, 17, 561-568.

34. Huang, Q.; Song, Z.; Rao, X.; Shang, S. Crystal structure of trikis(4,4'-bipyridine)bis $(N$ dimethylformamide)-copper(II) bis(perchlorate)-pyridine (1:2), $\left[\mathrm{Cu}\left(\mathrm{C}_{10} \mathrm{H}_{8} \mathrm{~N}_{2}\right)_{3}\left(\mathrm{C}_{3} \mathrm{H}_{7} \mathrm{O}\right)_{2}\right]\left[\mathrm{ClO}_{4}\right]_{2}$. $2 \mathrm{C}_{10} \mathrm{H}_{8} \mathrm{~N}_{2}$. Z. Kristallogr. NCS 2011, 226, 153-155.

35. Robson, R.; Abrahams, B.F.; Batten, S.R.; Gable, R.W.; Hoskins, B.F.; Liu, J. Crystal engineering of novel materials composed of infinite two- and three-dimensional frameworks. ACS Symp. Ser. 1992, 499, 256-273.

36. Dong, Y.-B.; Smith, M.D.; Layland, R.C.; zur Loye, H.-C. Novel hydrogen-bonded two- and three-dimensional networks generated from the reaction of metal nitrate hydrates $(\mathrm{M}=\mathrm{Cd}, \mathrm{Co})$ with the bidentate linear ligand 4,4'-bipyridine. J. Chem. Soc. Dalton Trans. 2000, 775-780.

37. Gao, J.; Wang, J.; Nie, J. $\mu-4,4$ '-bipyridine- $\kappa^{2} N: N^{\prime}$-bis[triaqua(4,4'-bipyridine- $\left.\kappa N\right)$ cadmium(II)] bis(3-aminobenzoate) bis(perchlorate) dihydrate: A novel supramolecular system constructed by $\mu-\mu$ and hydrogen-bonding interactions. Acta Cryst. 2011, C67, m181-m184.

38. Li, C.-P.; Du, M. Role of solvents in coordination supramolecular systems. Chem. Commun. 2011, 47, 5958-5972.

39. Nakamoto, K. Infrared and Raman Spectra of Inorganic and Coordination Compounds, 3rd ed.; John Wiley \& Sons: New York, NY, USA, 1978.

40. Rosenthal, M.R. The myth of the non-coordinating anion. J. Chem. Educ. 1973, 50, 331-335.

41. Wells, A.F. Three-Dimensional Nets and Polyhedra; Wiley: New York, NY, USA, 1977.

42. Candana, M.M.; Erogcirclu, S.; Oumlzbeya, S.; Kendi, E.; Kantarci, Z. Structure and conformation of 4,4'-bipyridine. Spectrosc. Lett. 1999, 32, 35-45.

43. Brock, C.P. Investigations of the systematics of crystal packing using the Cambridge Structural Database. J. Res. Natl. Inst. Stand. Technol. 1996, 101, 321-325.

44. Anderson, K.M.; Tallentire, S.E.; Probert, M.R.; Goeta, A.E.; Mendis, B.G.; Steed, J.W. Trimethyltin hydroxide: A Crystallographic and High Z' Curiosity. Cryst. Growth Des. 2011, 11, 820-826.

45. Steed, J.W. Should solid-state molecular packing have to obey the rules of crystallographic symmetry? CrystEngComm 2003, 5, 169-179.

46. Desiraju, G.R. On the presence of multiple molecules in the crystal asymmetric unit $\left(Z^{\prime}>1\right)$. CrystEngComm 2007, 9, 91-92.

47. Boag, N.M.; Coward, K.M.; Jones, A.C.; Pemble, M.E.; Thompson, J.R. 4,4'-Bipyridyl at 203 K. Acta Cryst. 1999, C55, 672-674.

48. Näther, C.; Riedel, J.; Jeß, I. 4,4'-Bipyridine dihydrate at 130 K. Acta Cryst. 2001, C57, 111-112. 
49. Lipton, A.S.; Mason, S.S.; Reger, D.L.; Ellis, P.D. ${ }^{113} \mathrm{Cd}$ shielding tensors of monomeric cadmium compounds containing nitrogen donor atoms. 1. CP/MAS studies on cadmium poly(pyrazolyl)borate complexes having $\mathrm{N}_{4}$ and $\mathrm{N}_{6}$ coordination environments. J. Am. Chem. Soc. 1994, 116, 10182-10187.

50. Mennitt, P.G.; Shatlock, M.P.; Bartuska, V.J.; Maciel, G.E. ${ }^{113}$ Cd NMR studies of solid Cadmium(II) complexes. J. Phys. Chem. 1981, 85, 2087-2091.

51. Osborne; A.G. Carbon-13 magnetic resonance spectral studies of some bipyridine derivatives. Monatsh. Chem. 1988, 119, 1385-1395.

52. Braga, D.; Palladino, G.; Polito, M.; Rubini, K.; Grepioni, F.; Chierotti, M.R.; Gobetto, R. Three polymorphic forms of the co-crystal 4,4'-bipyridine/pimelic acid and their structural, thermal, and spectroscopic characterization. Chem. Eur. J. 2008, 14, 10149-10159.

53. PROTEUM2. v.2.2-0; Bruker AXS Inc.: Madison, WI, USA, 2007.

54. SAINT. V7.46a; Bruker AXS Inc.: Madison, WI, USA, 2004.

55. Sheldrick, G.M. SADABS; University of Göttingen: Göttingen, Germany, 1996.

56. Palatinus, L.; Chapuis, G. SUPERFLIP — a computer program for the solution of crystal structures by charge flipping in arbitrary dimensions. J. Appl. Cryst. 2007, 40, 786-790.

57. van Smaalen, S.; Palatinus, L.; Schneider, M. The maximum-entropy method in superspace. Acta Cryst. 2003, A59, 459-469.

58. Sheldrick, G.M. A short history of SHELX. Acta Cryst. 2008, A64, 112-122.

59. Spek, A.L. Structure validation in chemical crystallography. Acta Cryst. 2009, D65, 148-155.

60. WinXPow; STOE \& Cie GmbH: Darmstadt, Germany, 2004.

61. Macrae, C.F.; Edgington, P.R.; McCabe, P.; Pidcock, E.; Shields, G.P.; Taylor, R.; Towler, M.; van de Streek, J. Mercury: Visualization and analysis of crystal structures. J. Appl. Cryst. 2006, 39, 453-457.

(C) 2011 by the authors; licensee MDPI, Basel, Switzerland. This article is an open access article distributed under the terms and conditions of the Creative Commons Attribution license (http://creativecommons.org/licenses/by/3.0/). 